\title{
Fifteen-minute consultation: Childhood burns: inflicted, neglect or accidental
}

\author{
Stephen Mullen, ${ }^{1}$ Roisin Begley, ${ }^{2}$ Zoe Roberts, ${ }^{2}$ Alison Mary Kemp ${ }^{3}$
}

\begin{abstract}
'Paediatric Emergency Department, Royal Belfast Hospital for Sick Children, Belfast, Northern Ireland ${ }^{2}$ Paediatric Emergency Department, University Hospital of Wales, Cardiff, UK ${ }^{3}$ Division of Population Medicine, School of Medicine, Cardiff University, Cardiff, UK
\end{abstract}

\section{Correspondence to} Dr Stephen Mullen, Royal Belfast Hospital for Sick Children, Belfast BT12 6BE, UK; drsmullen@gmail.com

Received 13 March 2018 Revised 15 May 2018 Accepted 16 May 2018 Published Online First 22 June 2018

\section{Check for updates}

To cite: Mullen S, Begley R, Roberts Z, et al. Arch Dis Child Educ Pract Ed 2019;104:74-78.

\begin{abstract}
Burns are a relatively common injury in children accounting for over 50000 emergency department attendances each year. An estimated 1 in 10 of these are due to maltreatment. These may present in the form of physical abuse or neglect with a reported ratio of 1:9. A burn associated with maltreatment may be a marker for future abuse or neglect and it is paramount that concerns are identified and addressed at the initial visit. Paediatricians need to be confident to identify safeguarding concerns specific to childhood burns and investigate accordingly. In this review, key variables that may aid in differentiating maltreatment from accidental burns are discussed in a case-based format, utilising up-to-date evidence to support the recommendations. Despite a proportion of burns resulting from physical abuse, the rate of child protection investigations in these patients are significantly lower than for children who present with other forms of physical injuries despite a similar proportion of positive findings. Our objective is to review the available evidence to support the safe assessment and management of children presenting with scalds or contact burns.
\end{abstract}

\section{INTRODUCTION}

While we are aware of the literature regarding physical abuse in the form of bruising and fractures, an area that can potentially be missed is the role child safeguarding plays in childhood burns. A burn is painful and distressing injury, enhancing the possibility of focusing solely on the physiology and failing to appreciate the wider safeguarding concerns.

The aim of this article is to review the literature on this topic.

\section{CASE}

You are on-call for general paediatrics in a busy district general hospital and are contacted by the emergency department
(ED). They have an 11-month-old with a burn and have some safeguarding concerns.

On the long walk down, you do a quick literature search on the safeguarding considerations with childhood burns.

\section{BACKGROUND}

There is good epidemiological data on childhood burns in the UK with approximately 50000 children attending ED each year with a burn. ${ }^{12}$ It is estimated that $10 \%$ of these are a result of maltreatment with the actual reported figure varying with geographical location. $^{3}$ In the UK estimates of 1\%-16\% are quoted and the US data estimates between 3\% and 26\%. ${ }^{4-6}$ Experts agree that the actual number is much higher.

Maltreatment in the case of burn injuries manifests in the form of neglect or physical abuse with the ratio of neglect to abuse $9: 1{ }^{7}$ As clinicians, we are all too aware of the importance of identifying child protection concerns early recognising that child abuse is an on-going process and not a solitary event.

Burns can be viewed as a marker for future maltreatment. The literatures identifies that if a child suffers a burn before the age of three, by their sixth birthday they are seven times more likely to suffer abuse or neglect and twice as likely to be a 'child in need' compared with a matched cohort. ${ }^{8}$

\section{CASE}

You further discuss the case with the ED team. The injury is reported to have occurred 2 days ago with no clear history. It is a deep partial thickness burn on both arms and legs, estimated at 2\%-3\%total body surface area (TBSA).

You consider what in the history and examination can belp you differentiate accidental burns from maltreatment burns (inflicted and neglect). 


\section{HISTORY}

- 'Toxic trio' (maternal mental health, domestic abuse, drug abuse)

- Changing mechanism or lack of mechanism of injury

- Reported mechanism does not fit with the developmental stage of the patient

- Presence or history of a social worker

- History of multiple previous attendances for injuries or previous burns

- A delay in presentation for medical review

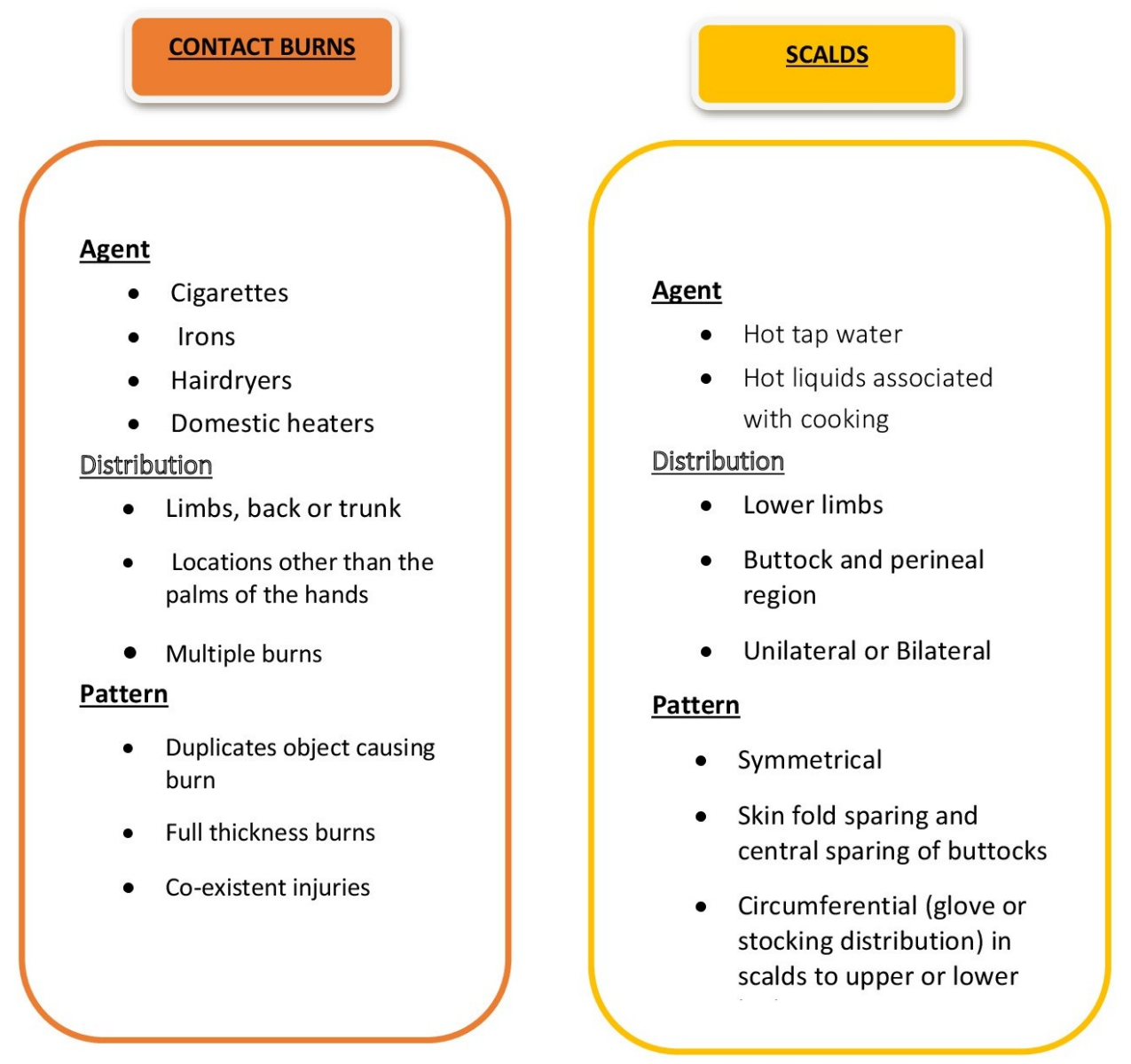

Figure 1 Features in history and examination that may be suggestive of maltreatment (neglect or physical abuse) in children with a burn.

\section{HISTORY}

A vague or changing history, an injury that does not fit with the history provided or a speculative account of an unwitnessed burn are potentially significant points for abusive burns and scalds. The blame of a sibling or a trigger event (family stress, persistently crying infant) also pose a higher risk for abuse. ${ }^{9}$ As with all paediatric injuries, the reported mechanism must be compatible with the developmental age of the child (figure 1).

Burns are a common cause of ED attendances, particularly in the under $5 \mathrm{~s}$. It is also these children who are most vulnerable with regard to abusive thermal injuries with abuse more likely in the younger patient. ${ }^{10}$
Socially, the presence of risk factors such as domestic violence and abuse, drug and alcohol misuse and severe mental health concerns in the carers, concern regarding level of supervision or the involvement of an active social worker for any reason, increase the potential for concern. ${ }^{11}$ Likewise, a history of multiple previous attendances for injuries or previous burns may be indicative of neglect or repeated physical abuse and further clarification should be sought. ${ }^{11}$

A delay in seeking treatment may be an indication of child maltreatment but in burn injuries, the rationale for delay can be more complex. The lack of pain in full thickness burns and the evolution of a burn from a superficial 


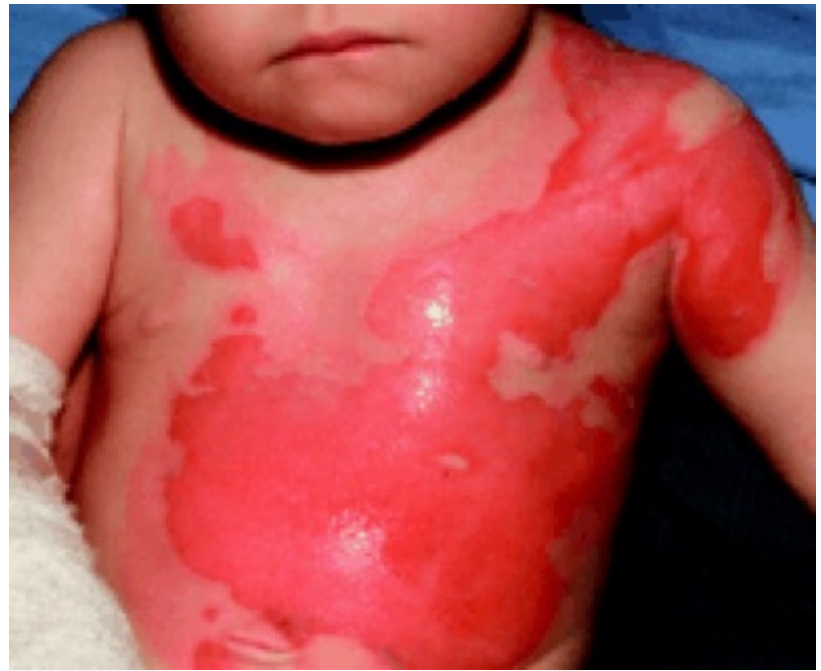

Figure 2 Pull down scald injury.

to deeper injury over time may account for some parents or carers delaying seeking medical advice.

There is some evidence to suggest that certain reported mechanisms may be more likely attributed to child maltreatment. One study found abuse was more likely if bathing ( $4 \%$ accidental vs $14 \%$ abusive) but less likely if reported to have occurred while cooking (25\% accidental vs $4 \%$ abusive) or due to a spill $(7 \%$ vs $1 \%) .{ }^{10}$ Pull down injuries, often from hot beverages, are one of the most common causes of accidental scalds in young children. While most are accidental, neglect and lack of supervision must always be considered. The youngest reported age for a pull-down scald was 8 months and a child able to climb into a bath was 16 months, highlighting the need for a detailed history and developmental assessment. ${ }^{12}$

While the absence of administrating first aid may be considered neglectful, there is no current evidence that supports this as a differentiating factor between

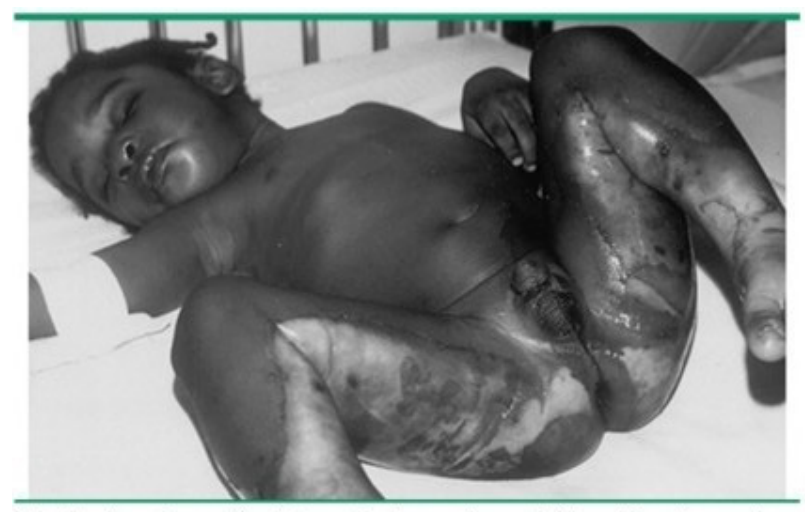

Note the sharp demarcation between the burn and normal skin and the absence of drip or splash marks, as well as the characteristic distribution on the buttocks and lower legs. Sparing of the thicker skin of palms or soles, and of skin folds where knees and hips are flexed, is also a common finding.

Reproduced with permission from: Reece RM, Ludwig S. Child Abuse: Medical Diagnosis and management, 2nd ed, Philadelphia: Lippincott Williams \& Wilkins, 2001. Copyright @ 2001 Lippincott Williams \& Wilkins. abusive and non-abusive thermal injuries. Studies show that parents' knowledge about appropriate first aid is poor. ${ }^{13}$ Burns first aid measures are simple but effective at reducing burn severity and should be a Public Health promotion priority.

\section{General examination}

It is important to include a development assessment, with an emphasis on correlating the mechanism of injury with the child's developmental stage. Consideration for child protection principles should be followed. Photographic imaging of injuries should be considered.

\section{Examination of the burn}

In this article, we will discuss the most common burns seen in childhood: scalds and contact burns. Remember that other types of burn may also present with child protection concerns.

A meticulous examination of the burn noting the depth, anatomical area involved, TBSA \% and pattern is paramount. There are certain characteristics of the burn itself that should evoke concern. Evidence has shown increased likelihood of abuse if a scald has bilateral pattern, TBSA >10\% and full thickness depth. ${ }^{9}$

\section{Scalds-non-inflicted}

Scalds are the most common burn injury accounting for $58 \%$ of all burns in children. ${ }^{12}$ Accidental scalds are frequently caused by spillages of hot drinks or hot liquid in food preparation and are found on the head, neck, trunk, face and upper body from the 'pull down mechanism' (figure 2). The burn pattern may demonstrate irregular margins, an irregular burn depth and asymmetrical involvement. It is important to consider evidence of neglect in the history when examining burns. Children may present with burns characteristic of accidental scalds due to lack of supervision .

\section{Scalds-inflicted}

Scalds due to maltreatment have been described to differ by site, depth, symmetry and the presence of sharply

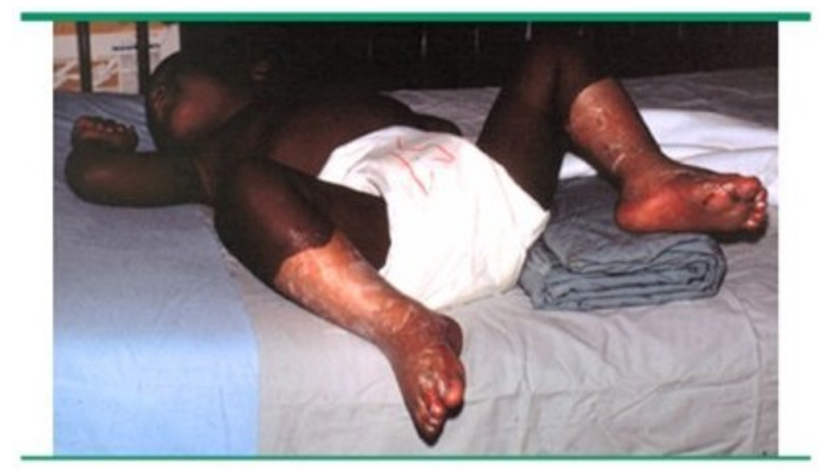

This pattern of deep symmetrical burns in a stocking distribution is typical for inflicted immersion injury.

Reproduced with permission from Stephen Ludwig, MD. 


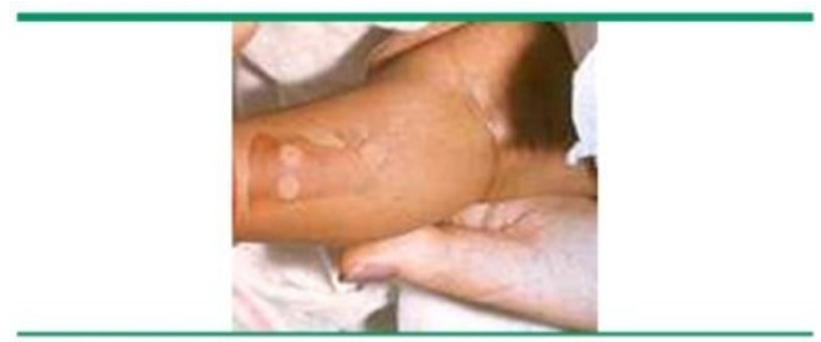

Note the imprint in the shape of a clothes iron.

Courtesy of Joan E Shook, MD.

Figure 5 Brand burn.

delineated borders. Inflicted scalds can be seen on the lower limbs, buttock and perineal regions and may be unilateral or bilateral. The typical pattern seen in forced immersion is a symmetrical burn to both sides of the body with clear margins, circumferential (glove and stocking pattern) and evidence of skin fold or central buttock sparing with uniform burn depth ${ }^{14}$ (figures 3 and 4).

The absence or presence of splash marks is no longer considered pathognomonic of child maltreatment. Children being held in water may struggle to get away from the scalding liquid (and so will have splash marks) and children who jump into a bath with hot water may 'freeze' giving themselves a symmetrical, unsplashed burn distribution. ${ }^{15}$ This highlights the importance of collating history, examination and further social and family information of this case and seeking expert advice where child protection concerns arise.

\section{Contact burns}

It can be difficult to differentiate between contact burns caused by maltreatment and those not. All contact burns are often clearly demarcated in the shape of the causative agent.

Children suffer accidental contact burns from irons, hair straighteners, oven doors or hobs. Accidental contact burns are predominantly caused by children touching hot objects and therefore seen on the fingers or palm of the hand ${ }^{12}$ (figure 5).

The most common reported cause of inflicted contact burns are from cigarettes, irons, hair dryers or domestic heaters. ${ }^{12}$ Burns may also occur from atypical instruments such as a hot spatula. ${ }^{14}$ Burns in inflicted contact burns can be found on the limbs, back or trunk and areas where the child themselves cannot reach. Burns are often multiple and may co-exist with other injuries suspicious of abuse $e^{9}$ (figure 6).

\section{CASE}

You have completed your history and examination. You do have some concerns that this case may be an inflicted injury and wonder what investigations, if any, you need to perform.

\section{INVESTIGATIONS}

It is important to remember that burns in cases of suspected child abuse are a sign of physical abuse or neglect. We would recommend that you adhere to your local safeguarding guidelines and consider referral to social services and for a child protection medical. The

\section{Burn marks}

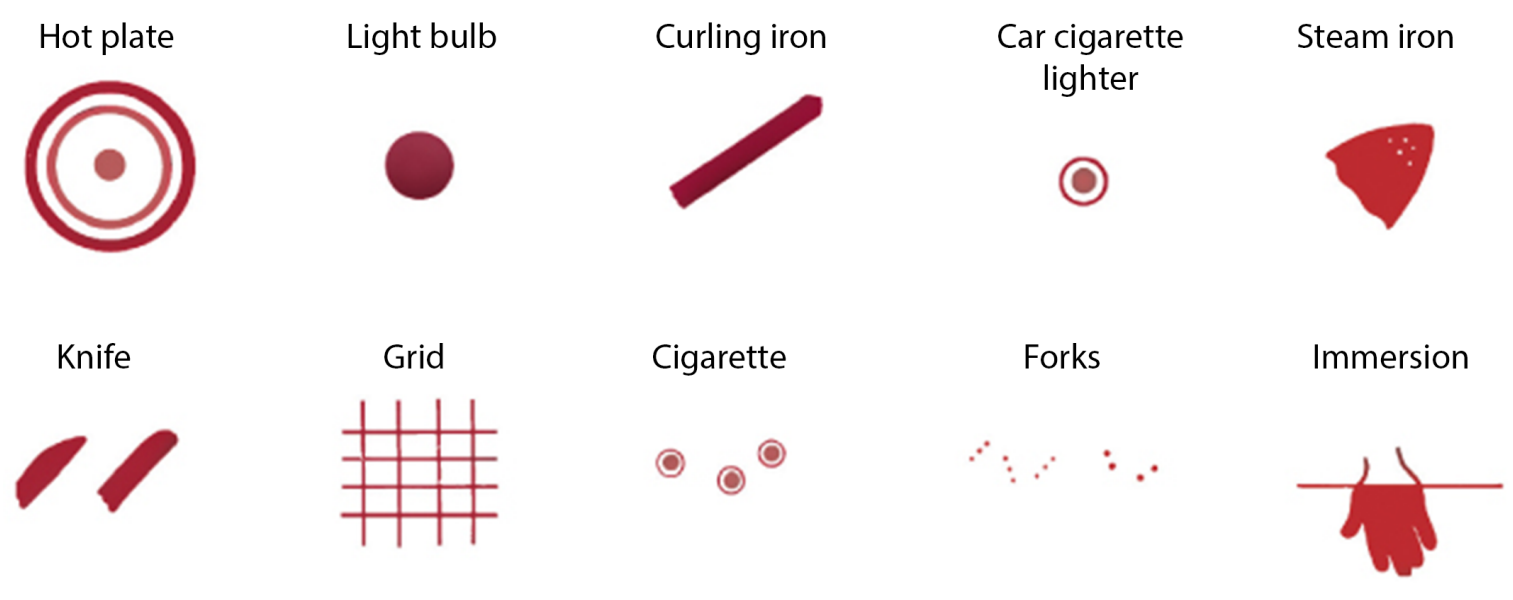

Marks from heated objects cause burns in a pattern that duplicates that of the object. Familiarity with the common heated objects that are used to traumatise children facilitates recognition of possible intentional injuries. The location of the burn is important in determining its cause. Children tend to explore surfaces with the palmar surface of the and rarely touch a heated object repeatedly or for a long time.

Reproduced from: Dubowitz H, Lane WG. Abused and neglected children. In: Nelson's Textbook of Pediatrics. Kliegman RM, Stanton BF, St Geme JW, Schor NF (Eds), 20th ed, Elsevier: Philapdelphia, 2015. Illustration used with permission of Elsevier Inc. All rights reserved.

Figure 6 Contact burn pattern suggesting abuse. 
Table 1 Comparing percentage of diagnostic investigations performed (bold) and percentage of positive results (in brackets) for children with burns versus* other, whom were referred to a Child Abuse Paediatricians. ${ }^{9}$

\begin{tabular}{lll}
\hline & Burns & Comparison \\
\hline CT head & $25 \%(+12 \%)$ & $61 \%(+44 \%)$ \\
Skeletal survey & $55 \%(+16 \%)$ & $\mathbf{7 2 \%}(+23 \%)$ \\
Transaminases & $35 \%(+2.6 \%)$ & $55 \%(+4.9 \%)$ \\
\hline
\end{tabular}

* Other included the remainder of children referred for child maltreatment investigations, that is, other forms of physical abuse, neglect and sexual abuse.

Royal College of Paediatrics and Child Health $(\mathrm{RCPCH})$ companion recommends that in children $<2$ years where physical abuse is suspected, investigations to exclude occult injury is required (eg, skeletal survey in those $<2$ years and cranial CT when $<1$ year of age). ${ }^{16}$ In children $>2$ years, further investigation should be decided on a case-by-case basis.

Despite these recommendations by the $\mathrm{RCPCH}$, the rate of investigations in children with burns is lower than when children present with bruises and other physical injuries ${ }^{9}$ (table 1). This is despite a comparable proportion of positive findings.

\section{Other considerations}

A home visit may collaborate facts and allow the collection of further evidence. This should occur in a detailed and forensic manner. A number of conditions have been mistaken for inflicted burns. ${ }^{11}$ It is important to include the multidisciplinary team in suspected cases of abuse. A formal review by a burns surgeon for their specialist input would be advisable, specifically commenting on the depth of injury, the degree of healing and their interpretation of the case.

\section{CLINICAL PREDICTION TOOL (CPT)}

The BuRN Tool is a CPT developed to aid clinicians in identifying child safeguarding concerns in children with burns. ${ }^{17}$ The tool is currently undergoing an implementation evaluation and pending these results, it may play a significant future role in the assessments of burns injuries.

\section{CONCLUSIONS}

Burns in childhood are a frequent presentation to EDs, with a significant proportion attributed to maltreatment. The recognition and initiation of child protection proceedings in these instances are imperative in preventing future harm to the patient. We recommend a detailed history, examination and a broader consideration of the social and historical background, appreciating that it is not one feature in isolation but an amalgamation of key variables that allows the clinician to appreciate the bigger picture.

Contributors SM conceived this review. SM, RB and ZR were all co-authors on this paper. AMK reviewed the final draft and helped develop this review.

Funding The authors have not declared a specific grant for this research from any funding agency in the public, commercial or not-for-profit sectors.

Competing interests SM and AK are undertaking research in the BuRN-Tool. Patient consent Not required.

Provenance and peer review Not commissioned; externally peer reviewed

(C) Article author(s) (or their employer(s) unless otherwise stated in the text of the article) 2019. All rights reserved. No commercial use is permitted unless otherwise expressly granted.

\section{REFERENCES}

1 Fenlon S, Nene S. Burns in children. BJA Educ 2007.

2 The Royal Society for the Prevention of Accidents. 24TH (FINAL) report of the home and leisure accident surveillance system [Internet]. Hass and Lass 2000 http://www.dti.gov.uk/ Pub (cited 2017 Feb 28).

3 Hayek SN, Wibbenmeyer LA, Kealey LD, et al. The efficacy of hair and urine toxicology screening on the detection of child abuse by burning. J Burn Care Res 2009;30:587-92.

4 Sheridan RL, Ryan CM, Petras LM, et al. Burns in children younger than two years of age: an experience with 200 consecutive admissions. Pediatrics 1997;100:721-3.

5 Hultman CS, Priolo D, Cairns BA, et al. Return to jeopardy: the fate of pediatric burn patients who are victims of abuse and neglect. J Burn Care Rehabil 1998;19:367-76.

6 Hobbs CJ. When are burns not accidental? Arch Dis Child 1986;61:357-61.

7 Chester DL, Jose RM, Aldlyami E, et al. Non-accidental burns in children-are we neglecting neglect? Burns 2006;32:222-8.

8 James-Ellison M, Barnes P, Maddocks A, et al. Social health outcomes following thermal injuries: a retrospective matched cohort study. Arch Dis Child 2009;94:663-7.

9 Pawlik MC, Kemp A, Maguire S, et al. Children with burns referred for child abuse evaluation: Burn characteristics and co-existent injuries. Child Abuse Negl 2016;55:52-61.

10 Hodgman EI, Pastorek RA, Saeman MR, et al. The Parkland Burn Center experience with 297 cases of child abuse from 1974 to 2010. Burns 2016;42:1121-7.

11 Maguire S. Which injuries may indicate child abuse? Arch Dis Child Educ Pract Ed 2010;95:170-7.

12 Kemp AM, Jones S, Lawson Z, et al. Patterns of burns and scalds in children. Arch Dis Child 2014;99:316-21.

13 Davies M, Maguire S, Okolie C, et al. How much do parents know about first aid for burns? Burns 2013;39:1083-90.

14 Royal College of Paediatrics and Child Health. Child Protection Evidence Systematic review on Burns. 2016 https://www.rcpch.ac.uk/system/files/protected/page/Child\% 20Protection\%20Evidence\%20-\%20Chapter\%20Burns Update_Final_270717.pdf.

15 Greenbaum AR, Donne J, Wilson D, et al. Intentional burn injury: an evidence-based, clinical and forensic review. Burns 2004;30:628-42.

16 RCPCH. Child protection companion. Second Edition, 2013.

17 Kemp AM, Hollén L, Emond AM, et al. Raising suspicion of mistreatment from burns: derivation and validation of the BuRN-Tool. Burns 2017 4179:30473-4. 